\title{
LUSOFONIA: A QUESTÃO DE GÊNERO, DIVERSIDADE E PODER
}

\author{
Cristina Novikoff ${ }^{1}$ \\ Maria Conceição Vinceprova Fonseca ${ }^{2}$ \\ Onireves Monteiro de Castro ${ }^{3}$
}

Resumo: Partindo dos pressupostos teóricos de Luis Antonio Verney (Portugal, século XVIII), assim como de sua proposta pedagógica de inclusão da mulher na sociedade, este artigo realiza um estudo de gênero, enfocando, a partir da contemporaneidade, o longo percurso da mulher em seu objetivo de, assim como o homem, atuar como sujeito desejante e relevante na escrita da História.

Palavras-chave: Mulher; Gênero; Lusofonia; Poder.

\section{LUSOPHONY: A FEW QUESTIONS OF GENDER AND POWER}

Abstract: Starting from Luis Antonio Verney's ( Portugal, $18^{\text {th }}$ century) theoretical concepts, as well as his pedagogical proposal of feminine social inclusion, this article constitutes a gender study which focuses, from the present perspective, on the long path women have walked to, similarly to men, act as important and effective desiring subjects in the writing of History.

Key words: Woman; Gender; Lusophony; Power.

[...] Agora, vida, só queremos que nos dês esperança para aguardar o dia luminoso que se avizinha quando mãos molhadas de ternura vierem erguer nossos corpos doridos submersos no pântano, quando nossas cabeças se puderem levantar novamente com dignidade

e formos novamente mulheres!

(Noémia de Sousa, "Moça das docas")

\footnotetext{
${ }^{1}$ Doutorado em Educação: Psicologia da Educação (PUCSP, 2006). Phd em Educação, com ênfase em Ensino da Pesquisa. Atua como professora no Mestrado em Letras e da Universidade Federal de Campina Grande - PROFLETRAS.

${ }^{2}$ Doutor em Letras pela Universidade Federal Fluminense (2009), com estágio na Faculdade de Tradução e Interpretação da Universidade de Ottawa (Canadá). Atua como professora do mestrado em Ensino em Ciências da Saúde e do Meio Ambiente da Fundação Oswaldo Aranha, Brasil/RJ.

3 Doutorado em Letras (Língua Portuguesa e Linguística) pela Universidade Federal da Paraíba (2005).Estágio Pós-Doutoral pela UFPB, concluído 2013. Atua no programa Mestrado em Letras e da Universidade Federal de Campina Grande - PROFLETRAS.
} 
Várias são as representações acerca da mulher no universo lusófono, muito embora, durante algum tempo, elas tenham convergido para imagens reducionistas. $\mathrm{Na}$ concepção cortês do amor, da qual ela é elemento basilar, temos o surgimento de uma ficção que a coloca à mercê de um fingimento desencadeado pelo homem que, apesar de referir-se à dama com deferência e mesmo a assumir a voz feminina, limita-se apenas a discorrer narcisicamente sobre o universo masculino. As cantigas de amor tornam-se, por isso, um texto perverso em que se lê o jogo entre silêncio e fala, visto que a clausura masculina assume um estatuto literário através da "dor de amor", ao passo que a dela é expressa por um texto que cerceia o fazer feminino, tornando a fin' amors uma expressão da univocidade característica daquele universo.

Séculos depois, ao retomar a Idade Média sob a perspectiva polifônica do romance, José Saramago, em Levantado do chão (1979), reencena as Cantigas de Amigo ao descrever à ida à fonte de uma mulher, ancestral da família Mau Tempo retratada nessa obra, colocando-a como parte da história de Portugal ao descrever o surgimento da "trindade perfeita": Latifúndio, Igreja e Estado. Tal latifúndio é representado pela descendência de Lamberto Horques Alemão, "alcaide-mor de Monte Lavre por mercê do rei Dom João I" (SARAMAGO, 1979, p. 24), que inaugura uma linhagem de grandes donos da terra através do casamento cristão de que descendem Dagoberto, Alberto, Norberto, Floriberto, Gilberto, Berto, Sigisberto, Adalberto, Angilberto, Ansberto e Contraberto, de fins do século XV à contemporaneidade enunciada. É nesse cenário que o locus amenus trovadoresco é alterado pela violação dessa mulher pelo patriarca alemão, cujo ultraje será rememorado a cada duas gerações com crianças com olhos azuis que assinalam a bastardia e errância que bem traduzem a semântica de seu sobrenome.

A etimologia do sufixo "berto" é relevante, pois significa "luz" e "brilho" que caracteriza o discurso da história oficial subjacente aos campos de cultivo do Alentejo (SILVA, 1989, p. 266), resultando na inversão do discurso bíblico que caracteriza o latifúndio: em vez de "crescer e multiplicai-vos", torna-se "crescei e multiplicai-me", segundo a enunciação irônica do romance (SARAMAGO, 1979, p. 14). Todavia, fazendo valer a premissa de que "mudam-se os tempos, mudam-se as vontades", a ficção entretecida à história mostra que também o papel das mulheres começa a mudar, visto que as diversas revoluções acarretam alterações na vida, nos costumes e nas leis.

RPI Revista de Pesquisa Interdisciplinar, Cajazeiras, v. 2, n. 2, 217-234, jun/dez. de 2017. 
Assim, a faceta que melhor as caracterizam ocorre na terceira geração dos Mau Tempo, através do casamento de Gracinda com Manuel Espada que, a partir de então, deixa de lado a má sina do nome paterno para assumir o do marido, marcado pelo brilho do metal que caracteriza as diversas transformações ocorridas em Portugal e que se dá, especificamente, no nascimento de Maria Adelaide, filha do casal.

Ao justapor o nascimento da menina ao de Jesus Cristo e assinalá-lo como o despontar de um "sol de justiça" (SARAMAGO, 1979, p. 364), a enunciação aproximase diacronicamente da insurreição vitoriosa que preludia a "Revolução dos Cravos" e as transformações decorrentes. A menina de olhos azuis tem, portanto grande relevância nesta epopeia campesina, sobretudo se pensarmos que este gênero sempre foi caracterizado por herois masculinos. Tanto os fatos inerentes ao seu nascimento quanto a etimologia de "Adelaide" que, como o nomes do "bertos", também significa "brilho" e "luz" (SILVA, 1989, p. 259), alçam-na à categoria de representante dos novos tempos em que a espada abre "o caminho, sendo luz da lâmina brilhante para o "sol de justiça" (SILVA, 1989, p. 259) que anula a opressão do passado, revelando novas expectativas.

Tal qual o romance de Saramago, muitos são os exemplos que viabilizam os estudos de gênero nas literaturas de expressão portuguesa. Partindo, todavia, das breves considerações literárias suscitadas por Levantado do chão para observações críticoteóricas, lemos que, em seu artigo "Gênero: uma categoria útil de análise histórica", Joan Scott afirma que sua conceituação surgiu em oposição a um determinismo biológico nas relações entre os sexos, dando-lhe um caráter fundamentalmente social. Para ela, "o gênero enfatizava igualmente o aspecto relacional das definições normativas da feminidade" (SCOTT, 1990, p. 5) oriundo da preocupação de que os estudos sobre a mulher ainda a considerassem sob uma perspectiva demasiadamente limitada. Esta nova modalidade científica mostra que homens e mulheres são definidos em termos recíprocos e não podem ser entendidos separadamente. Por referir-se a um código de conduta que rege a organização social, o uso do termo "gênero" passou a substituir a palavra "sexo" que, etimologicamente, distingue macho de fêmea para sublinhar seu contributo social.

Ademais, o gênero como categoria analítica possui, tanto na História quanto na Literatura e em outros campos de saber crítico a vantagem de propor uma substituição dos paradigmas do conhecimento tradicional, não apenas pela inserção de novos temas, 
mas por "um reexame crítico das premissas e dos critérios do trabalho científico existente" (SCOTT, 1990, p. 6). Paralelamente às noções já conhecidas de classe e de raça, ele viabilizaria o discurso dos "oprimidos" a partir da verticalização do sentido e da natureza desta opressão.

A preocupação com a história das mulheres foi incrementada nos anos 60 através do movimento feminista, que demandava sua participação efetiva na escrita da História. Entretanto, como pontua a estudiosa, nos anos 70, a historiografia feminina teria se afastado da política para, na década seguinte, romper definitivamente com ela, fato concomitante ao surgimento do termo "gênero", na altura aparentemente neutro e sem propósito. Para ela, a emergência da história das mulheres como um campo de estudo envolve "uma evolução do feminismo para as mulheres e daí para o gênero; ou seja, da política para a história especializada e daí para a análise" (SCOTT, 1992, p. 6465). Por isso, Scott acredita em sua emergência como um sinal de despolitização e neutralidade que ampliaria a gama de suas especificidades, uma vez que esta narrativa demanda uma reflexão crítica não apenas por sua simplicidade, mas por não representar por completo a História da história das mulheres e seu relacionamento tanto com a política quanto com a disciplina da história. Desse modo, antigas concepções atrelavam suas perspectivas ao movimento feminista ou a aspectos restritos às especificidades do lar, abrangendo o domínio cotidiano do mundo e da sociedade a partir da diversidade de suas múltiplas hierarquizações, conexões e relações de/com o poder. A partir desta compreensão, a noção de gênero passa a ser percebida como "efeito", substituindo um sujeito centrado, um sentido em si do sujeito.

Não obstante esta percepção tenha sido, reafirmamos, implementada a partir do século XX, houve ao longo da história alguns movimentos que anteciparam a compreensão das mulheres e de sua participação na sociedade de um modo mais abrangente e vanguardista. Cabe-nos elucidá-lo através de uma análise que também leve em conta aspectos políticos e éticos que comparecem à discussão.

É disto que trata este artigo. 


\section{Luis António Verney e a pedagogia iluminista em Portugal}

Retomando as considerações sobre o gênero e lusofonia associados à história de Portugal, chegamos a um dos momentos iniciais de transformações do quadro de subalternidade a que a mulher esteve associada. Simultaneamente à ascensão de Sebastião José de Carvalho e Melo, o Marquês de Pombal, o Iluminismo português caracterizou-se por uma drástica reação à intolerância à religiosa, sobretudo à Inquisição, e o grande êxodo de intelectuais portugueses para o exterior. Este movimento adquiriu uma feição de Estado, unindo-se a um exercício político de contestação e combate ao atraso provocado pela Companhia de Jesus e sua pedagogia excludente, apesar de seu viés cultural.

Filiada esteticamente ao Neoclassicismo (1756-1825), a época caracterizou-se por propostas de renovação que, apesar de surgidas na Inglaterra, tiveram seu apogeu na Revolução Francesa, ou seja, no pleno reconhecimento dos ideais de "liberdade, igualdade e fraternidade" que também foram incorporados pela política expansionista de D. João V.

Com efeito, através do desenvolvimento da burguesia, o movimento teve grande influência na educação que, da esfera teológica, transfigurou-se por intermédio de uma estruturação laica, sobretudo porque a razão foi tida como fonte do pleno conhecimento que iluminaria o atraso em Portugal através de um diálogo mais intenso com o restante da Europa. Através de postulados anticlericais que aplicavam maior rigor à religião e à análise dos textos sagrados, o movimento teve por base posições antiaristotélicas e antiformalistas; a valorização do prazer e da educação como moldes do homem e de seu desenvolvimento pleno através do culto da simplicidade e da verossimilhança.

É neste contexto que D. João V promoveu ampla reforma cultural, convocando artistas estrangeiros e portugueses a ali trabalharem, expandindo, consequentemente, as artes através da criação de instituições, como a Academia Real das Ciências (1779), e, no que concerne a este artigo, a contratação de Luís António Verney (1713-1792) e a promoção de notável transformação pedagógica.

Nascido em Lisboa e falecido em Roma, Verney estudou Filosofia em seu país e Teologia na Itália. Graduado, retornou a Évora a fim de lecionar e aplicar suas ideias. 
Todavia, apesar de haver sido nomeado arquidiácono na catedral metropolitana desta cidade, regressou a Roma, em 1749, pois suas propostas não foram aceitas.

Como mencionamos, a base da educação em Portugal advinha de uma formação católica, mais especificamente, da escola jesuíta. Nomes de prestígio, ainda que associados à religião, como Manuel Alexandre de Figueiredo que, em 1734 publicou $A$ Nova escola para aprender a ler, escrever e contar e Martinho de Mendonça Pina e Proença, com Apontamentos para a educação de um menino nobre (1734) preconizaram métodos de ensino que se opunham ao sistema aristotélico e privilegiavam o despotismo que, contudo, não tiveram o impacto produzido pelas propostas sociais de Verney. Tal se deu porque, para este autor, ensino e educação deveriam abranger todos os campos do saber com um nível inédito de inclusão que não envolvia apenas os homens, uma vez que "a educação das mulheres neste Reino é péssima; e os homens quase as consideram como animais de outra espécie; e não são pouco aptas, mas incapazes de qualquer gênero de estudo e erudição" (VERNEY, 1949, v.1, p. 141).

Apesar da racionalidade iluminista e da crença de que "o homem poderia se emancipar através da razão e do saber a que todos deveriam ter acesso" (JAPIASSU e MARCONDES, 1990, p. 128), alguns aspectos relevantes da vida cotidiana, como os de inclusão e de gênero, não foram prestigiados naquele sistema cultural. Assim, não é de se estranhar a recusa às propostas de Verney.

No quinto volume do Verdadeiro método de estudar, Verney propõe um processo de aprendizagem das mulheres partindo de sua pretensa inferioridade à necessidade de seu aprimoramento intelectual que decorreria de conhecimentos de Gramática, Aritmética, Geografia e História - religiosa, clássica e portuguesa -, bem como o estudo de Economia doméstica, Canto, Dança e Latim. Esta língua deveria ser dominada não apenas pelas freiras - que liam, mas nem sempre entendiam os textos religiosos -, mas por mulheres em geral que, semelhantemente, "tirariam mais utilidade de ler os livros" (p. 148).

Verney ressalta que tal inferioridade resulta de mera conformação social, afirmando que, no que tange "à capacidade, é loucura persuadir-se que as mulheres tenham menos que os homens", para, em seguida, ressaltar que, se lhes fosse permitido o acesso às letras, “então veríamos quem reinava” (VERNEY, 1949, p. 124-125). 
Na verdade, percebe-se em suas intenções uma alteração no status feminino que, do de serviçal passaria ao de educadora, administrando tanto a casa quanto orientando seus filhos. Estas limitar-se-ão aos ensinamentos maternos, ao passo que os homens continuarão sua formação em estabelecimentos formais de ensino. Salgado Júnior, organizador da edição da obra de Verney, compara sua teoria com a de Fénelon, na Éducation des filles, publicada em 1687, e a de M. Rollin, no Traité des Études (17261728), ressaltando sua influência no educador português.

Apesar de inovadoras, deve-se ressaltar que suas propostas são de viés utilitário, pois limitam a atuação feminina ao espaço do lar, organizando-o, administrando-o e aprimorando-se nas restritas rodas sociais e, sobretudo, zelando por uma educação dos filhos em conformidade aos novos padrões. A aprendizagem da economia também possui aspectos práticos: a burguesia emergente, oscilando entre os efeitos da ascensão social e a ignorância resultante da falta de estudos formais, preocupava-se em ostentar, comprometendo o capital necessário à manutenção da casa. No capítulo intitulado "Estudos especializados de economia doméstica, o autor distingue o "Conhecimento cabal do governo da casa" dos "Lavores femininos", em que recomenda o domínio da arte de coser, bordar e remendar. Outra preocupação inovadora é com a viuvez, pois, nestas condições, caberia a mulher administrar as rendas da família, zelando pelo seu sustento.

Interessante é observar que o estudo linguístico proposto seria a partir de textos bíblicos, o único modelo disponível, o que, todavia, contrasta com a leitura da literatura clássica, plena de divindades pagãs que interrogam o cânone religioso. Ao propor uma metodologia associada ao raciocínio crítico, Verney apresenta o que é o ponto alto de sua pedagogia: a aprendizagem associada ao prazer (VERNEY, 1949, p. 13). Por isso, ao contrário de Fénelon, recomenda a leitura de poetas e a apreciação da música e da dança com o intuito de entretenimento, antes considerado prejudicial. Deve-se, todavia, limitar os gastos nessa empreitada e limitá-las somente ao deleite e a alguma atividade física, pois não cabe às senhoras casadas exercê-las profissionalmente. Às freiras, recomenda-se apenas tocar órgão, ou seja, uma atividade restrita ao ambiente religioso.

As propostas de Verney quanto ao ensino e à educação abrangem diversos campos do saber não apenas pela inclusão que faz das mulheres no processo social, mas quanto à crítica dirigida aos que as consideravam "animais de outra espécie" 
(VERNEY, 1949, v.1, p. 141). Sua leitura aclara questões ligadas não apenas a um tatear precoce das questões de gênero, apresentando-nos a uma crítica social perceptível através da prosa didática que sua escrita inaugura.

Através d'O Verdadeiro método de estudar, obra composta por dezesseis cartas enviadas de Roma a um doutor da Universidade de Coimbra, Verney propõe a modificação do ensino superior em Portugal, defendendo ineditamente, ainda que até certo ponto, as liberdades individuais. $\mathrm{O}$ ineditismo de suas propostas resultou numa universidade laica que fez com que o método didático-pedagógico passasse a vigorar em Portugal alçando-o ao nível de outras nações europeias.

Com o objetivo de orientar as escolas e fundar a nova estrutura pedagógica, as cartas são divididas nos seguintes tópicos: 1. Língua Portuguesa; 2. Gramática latina; 3. Latinidade; 4. Grego, Hebraico e línguas modernas; 5 e 6. Retórica; 7. Poesia; 8. Lógica; 9. Metafísica; 10. Física; 11. Ética; 12. Medicina; 13. Direito civil; 14. Teologia; 15. Direito canônico; 16. Regulamentação geral dos estudos.

Ao organizar a edição portuguesa, Salgado Júnior o fez em cinco volumes, assim distribuídos: 1. Estudos linguísticos (cartas 1 a 4); 2. Estudos literários (cartas 5 a 7); Estudos filosóficos (cartas 8 a 11); Estudos médicos, jurídicos e teológicos (cartas 12 a 14) e Estudos canônicos, regulamentação e sinopse (cartas 14 e 16).

Tendo como base uma "lógica natural", Verney acredita na simplificação e ampliação do ensino, combatendo o abuso do silogismo e os excessos do Barroco e uma práxis centrada apenas na memorização e não no prazer e vivência real das situações propostas. Por isso, não há razão para "carregar a memória dos pobres estudantes com uma infinidade de versos latinos e outras coisas que não servem para nada neste mundo" (VERNEY, 1949, p. 141). Adiante, acrescenta que "a outra coisa que se deve reprovar é que obriguem os rapazes a aprender três sortes de regras - em verso, em prosa latina e em prosa vulgar”. Isto, “quando não lhe queiramos dar outro nome, é perder tempo sem utilidade e com prejuízo grande, sem haver outra necessidade que seguir um costume envelhecido, ainda que prejudicial” (p. 143).

Ao defender a simplificação do ensino, Verney condena o discurso demasiadamente elaborado em favor de um "estilo simples" que leva à compreensão e decodificação da mensagem. Por isso, criticou nomes consagrados da literatura portuguesa, como Camões e Jerônimo Baía por usarem versos, segundo ele, “contrários 
à boa razão", fato que, como é de se esperar, provocou polêmica. Ainda no plano prático, defende preceitos metodológicos e epistemológicos, usando a taxonomia, a descrição e o empirismo como bases de seu método, o que também provocou crítica das esferas conservadoras.

Dessa maneira, podemos perceber que, ainda que experimentalmente, Luis António Verney antecipou-se a eventos que ocorreriam no futuro ao preocupar-se com a posição da mulher portuguesa na sociedade e sua contribuição ao desenvolvimento. Retomando o que afirmamos na primeira parte deste texto, os estudos de gênero podem, então, ser entendidos como um conjunto de saberes cujo objetivo é proporcionar categorias e metodologias para análise das representações e condições de existência de homens e mulheres em sociedades passadas e futuras (YANNOULAS, 2001, p. 426) a partir de pontos como a comparatividade, transversalidade, politicidade e espacialidade que apresentam as marcas da diferença e da autonomia.

$\mathrm{Na}$ perspectiva feminina, nenhum outro autor português havia se preocupado com o ensino das mulheres, a não ser Francisco Manuel de Melo, que, na Carta de guia de casados (1651), faz menção à elas, ditando-lhes, todavia, regras de comportamento (RECTOR, 2002, p. 78). Muito embora a filosofia iluminista tenha dado voz a nomes como Gertrudes Margarida de Jesus, autora da Primeira carta apologética em favor e em defesa das mulheres (1761) e a Teresa Margarida da Silva e Orta, Marquesa de Alorna, foi Luis António Verney quem verdadeiramente trabalhou na defesa e na difusão do ensino das mulheres.

Da perspectiva de Verney de que as mulheres guardam lugar e condição de humanidade similares à do homem fica a pergunta: como, nos espaços estruturais da sociedade capitalista, as mulheres efetivam esta condição? É essa discussão que nos conduz ao próximo tópico.

\section{Estrutura-ação das sociedades capitalistas de Santos (2002) e a questão de gênero}

Tomando como referencia a análise estrutural desenvolvida por Boaventura de Sousa e Santos (2002, p. 273) podemos refletir sobre o lugar/condição das mulheres atualmente. Vimos, em Verney, sua luta por melhoria e/ou inserção na educação para além do espaço doméstico. Cabe-nos agora confrontar sua efetivação, analisando a 
teoria de Santos através dos seis "espaços" e dimensões de análise: Unidade de prática social, Instituições; Dinâmica de desenvolvimento; Forma de poder; Forma de Direito; Forma Epistemológica. Cabe-nos salientar que esta gralha é sustentada por duas teorias sociológicas críticas, permitindo uma visão analítica livre de reducionismo ao totalitarismo, mas de distinção para que compreendamos a implicação das lutas de poder na configuração da estrutura social vigente. Em cada espaço, o ente se faz presente na dimensão de outro espaço, mesclando-se, alimentando-se. São eles:

a) Espaço doméstico: Marcado pela prática social de diferença sexual e geracional dentro da instituição casamento, família e parentesco; sua dinâmica de desenvolvimento se faz pela maximização da afetividade, seu poder é dado pelo patriarcado e a forma de direito é o doméstico (espaço privado) e a sua forma epistemológica é o "familiarismo", a cultura familiar.

b) Espaço da produção: Desenvolve-se nas relações de valores econômicos e de processo de trabalho que hoje é institucionalizado nas empresas, fábricas e mesmo em casa; desenvolvido sob a maximização do lucro da degradação da natureza, é marcado pela exploração do trabalho com direito apenas a produção; descrito pelo produtivismo, tecnologicismo, formação profissional e cultura empresarial.

c) Espaço de mercado: Tem a unidade de prática social como a relação clienteconsumidor; representa o mercado; maximiza a utilidade e a mercadorização das necessidades; a forma de poder é dada pelo/no fetichismo das mercadorias; o direito é de troca e sua forma epistemológica é pelo consumismo e a cultura de massa.

d) Espaço da comunidade: A unidade de prática social é a etnicidade, a raça, a nação, o povo e a religião; se institui na comunidade, vizinhança, região, bem como em organizações populares de base, como igrejas; desenvolve-se pela maximização da identidade; o poder é marcado pela diferenciação desigual; o direito é da comunidade e sua forma de conhecimento é o local, cultural da comunidade e da tradição.

e) Espaço da cidadania: A prática reside na própria cidadania e sua instituição, ou seja, o Estado; sua dinâmica de desenvolvimento é a maximização da lealdade; a forma de poder se faz pela dominação; o direito é o territorial (estatal) e sua forma epistemológica é o Nacionalismo educacional e cultural, a cultura cívica. 
f) Espaço mundial: Sua unidade de prática social é mantida pelo Estado-Nação; sua representatividade institucional é o sistema inter-estatal, organismos e associações e tratados internacionais; sua dinâmica de desenvolvimento se alimenta da maximização da eficácia; a forma de poder é dada via troca desigual; o direito é o sistêmico e sua epistemologia formatada pela idéia de ciência, progresso universalístico, cultura global.

Iniciando nossa análise pelo espaço doméstico, tomamos o exemplo do sociólogo para explicar como cada um desses espaços se encontra em dimensões de forma relacional:

[...] a forma privilegiada de prática social no espaço doméstico é a diferença sexual e geracional, mas isto não significa - como as teorias femininas mostraram convincentemente - que o sexo e a geração estejam confinados ao espaço doméstico. Pelo contrário, e para tomar o exemplo da diferença sexual, o sexo combina-se especificamente com a classe no espaço de produção, com o cliente-consumidor no espaço de mercado, com a raça, a etnicidade ou a religião no espaço da comunidade, com a cidadania no espaço cidadania e com a nação e as práticas do Estado-nação no espaço mundial. O mesmo pode ser dito de qualquer das outras dimensões (SANTOS, 2000, p. 278).

Continuando pelo espaço doméstico, observamos que as mulheres continuam se assumindo como responsáveis pelas atividades domésticas e os homens como seus ajudantes, segundo o estudo de Lago et ali (2009). Nele são analisadas as relações dos sujeitos com seus espaços de vida familiar e os valores e as subjetividades. Tal delineamento de papéis reforça a teoria de Santos de que a forma de direito é marcada pelo patriarcado e sua forma de produção o é pela cultura familiar em que a busca pelo pertencimento é impulsionada pela afetividade.

No espaço de produção, podemos nos ancorar em Lavinas (2001) e a empregabilidade feminina no Brasil. A pesquisa da Economista do Programa de Segurança Sócio-Econômica do Departamento Internacional do Trabalho (ILO) diz que

[...] o diferencial de gênero que capacita as mulheres a disputarem espaço no mercado de trabalho com mais sucesso do que os homens é seu nível médio de escolaridade mais alto (37\%) e seu patamar de remuneração (25\%), ainda inferior. Entretanto, seu maior "grau de empregabilidade" se deve à dimensão de gênero. É como se as

RPI Revista de Pesquisa Interdisciplinar, Cajazeiras, v. 2, n. 2, 217-234, jun/dez. de 2017. 
habilidades "femininas" ou um tipo de atributo pessoal credenciado pela dimensão de gênero, hoje fortemente demandados pela "nova economia", somados a vantagens objetivas (escolaridade e menor custo de contratação), permitissem às mulheres realizar ganhos de diferencial sumamente importantes (LAVINAS, 2001, p.18).

É notória a exploração da mão-de-obra feminina, cujas relações trabalhistas, apesar de permitirem ganhos às mulheres, estão aquém da sua mais-valia. As mulheres neste espaço têm algumas características ainda associadas à menos-valia, como responsáveis por compatibilizar o trabalho doméstico e trabalho remunerado; sofrer o estereótipo de mão-de-obra secundária, sujeitando-se a salários inferiores e aos denominados "empregos temporários" do setor público e privado, sendo, igualmente, as primeiras a serem dispensadas pelo baixo poder de barganha. (LAVINAS, 2001, p. 24).

A economista aponta que "existiria um trade-off" entre elevação da taxa de emprego feminino, ou uma feminização do emprego que resulta na precarização das relações de trabalho" (LAVINAS, 2001, p. 1). As razões apontadas para este conflito não são de natureza econômica, mas sociológica, "relacionadas à busca de autonomia e igualdade, às mudanças nos arranjos familiares com crescimento das famílias monoparentais chefiadas por mulheres" (LAVINAS, 2001, p. 2).

A invisibilidade da mulher no espaço de produção é percebida por pesquisas de áreas distintas (Psicologia social, Sociologia, História, Educação, etc.), seguindo uma lógica similar de denotar a diferença entre homens e mulheres para o trabalho e maisvalia. Entre os lugares de produção feminina encontram-se o Serviço Social, a Enfermagem, a Educação como representações da subalternidade profissional.

Dutra (2013) traça a saga de mulheres africanas que trazem as "marcas de subalternidade comuns a outros desterritorializados, fazendo-nos ver que a diáspora pode perpetuar, em diversos tempos e níveis, o mesmo infortúnio dos que foram embarcados nos muitos navios negreiros que aqui aportaram (DUTRA, 2013, p.29)

Apesar de o Censo da Educação Superior, realizado em 2009, no Brasil, indicar as mulheres como a maioria entre os estudantes universitários, tanto na graduação presencial $(55,1 \%)$ como à distância $(69,2 \%)$, bem como de permanência com 58,8\% do total de concluintes na primeira modalidade de ensino e de $76,2 \%$ na segunda, ainda assim a opção de formação é delimitada pela luta de poder dos "espaços de estrutura- 
ação", forçando uma subalternidade hierárquica, política e ética na "escolha" profissional que merece ser pensada.

Barletto et ali (2010) apresentam pesquisas que tratam o tema da mulher e a academia, resgatando o trabalho de Londa Schiebinger sobre o acesso das mulheres à universidade, assinalando que a ciência é retratada como lugar que privilegia homens e, a academia, as mulheres. A autora busca discutir o problema de como aumentar o número de mulheres nas instituiçõos universitárias e na produção de conhecimento científico.

A invisibilidade da mulher na área das engenharias e tecnologia em geral ainda se faz notar com apenas $45 \%$ de representação nestes campos do saber. Os números acusam uma relação entre ciência e escolha profissional que remonta ao espaço doméstico e de cidadania que, por sua vez, reforçam representações sociais sobre as questões sexuais e configuram práticas que tendem a reforçar a lógica do determinismo biológico ou cultural justificado na ideia de vocação ou aptidão inata para determinados cursos e/ou formação profissional.

Em relação ao espaço de mercado, a mulher é marcada pela maximização da utilidade e a mercadorização das necessidades quando serve de produto para vender produto e, assim, ser coisificada. Do mesmo modo, Lessa (2005), ancorada nas perspectivas feministas, discute a banalização das imagens femininas "como um retrocesso nas conquistas sociais e políticas das mulheres, entendendo a proliferação dessas imagens como uma causa da reprodução de valores e da consolidação de um modelo de feminino" (BARLETTO, 2010, p. 834).

Compreendemos que as representações sociais de homens sobre as mulheres, apesar de promoverem uma subjetivação feminina eivada da subjetividade masculina de domínio, prazer e poder de subjugar se processa em três níveis, segundo Milanez (2004). O primeiro, do poder representado pelo Ser-saber é configurado pelo imaginário figurativo sendo, portanto, visível e enunciado; o segundo, denominado de Ser-poder, manifesta-se nas relações de força e o terceiro, o Ser-si determina-se pelos processos de subjetivação. Outrossim, as representações sociais vigentes que o sexo masculino ainda guarda manifestam-se no patriarcado e na pretensa condição de deliberar sobre a mulher, seu corpo e sua alma). Logo, expressam valores que implicam a configuração das representações atuais e sua efetivação. Assim, a idéia de fetichismo das mercadorias 
se entrelaça à idéia de poder do homem e da sociedade ainda masculina, gerando a luta de poder marcada pela subjugação da mulher, apesar das conquistas legais. Cabe apontar que estas representações são, todavia, parte do imaginário de muitas mulheres, que as aceitam e apreciam, colocando-se na posição de objeto, bem como de outras que as rejeitam o discurso, mas, na prática, posicionam-se como mercadoria.

A mulher frente ao espaço de comunidade é bem entendida nos estudos culturais e em diálogos com as Ciências Sociais e Humanas, na Antropologia, na Literatura e nas Artes. Uma análise interessante sobre diferentes textos sobre gênero é o estudo cultural de Messanos (2011), que nos permite perceber como o gênero transita entre distintos termos e sentidos sobre o ser mulher. Um termo muito adotado é de "feminismo" perpassado pela discussão política, social ou ética sobre o lugar da mulher na sociedade. Outro que se faz presente é "feminilidade", termo cercado da idéia de caráter próprio de mulher. Em outra perspectiva tem-se "feminidade", ou seja, remete à idéia daquilo que constitui o caráter de quem é mulher.

No espaço de cidadania instituído pelo Estado, o gênero pode ser entendido, retomando Scott, ao analisarmos este conceito frente à política e ao poder percebidos como territórios praticamente inexplorados, na medida em que a história política "foi o bastião da resistência à inclusão de materiais ou questões sobre as mulheres e o gênero" (BRITO, 2001, p. 293).

Esta ideia se explicita no fato de que expressões femininas na política, ainda hoje, são sustentadas pelo imaginário masculino que as referencia, tentando prolongar ad infinitum a semântica que, como vimos, foi subjacente aos Mau Tempo. Todavia, alguns esforços têm sido feitos no âmbito da lusofonia, através de vozes que se levantaram contra este status quo, de modo a dar-lhes voz. Seja na Literatura, como no caso de Maria Firmina dos Reis, autora do primeiro romance abolicionista publicado no Brasil, ainda que sob pseudônimo, ou de Conceição Evaristo, afrodescendente que ainda explicita em seus textos casos de segregação e preconceito ocorridos no Brasil mostrando que no século que as separam não houve as mudanças desejadas quanto à inclusão de gênero. Assim são as vozes de Noémia de Sousa, Alda Lara e Alda Espírito Santo, cuja escrita embalou a utopia que resultou na Revolução Colonial e a libertação dos países africanos de que são oriundas ou, na atualidade, através de Dina Salústio,

RPI Revista de Pesquisa Interdisciplinar, Cajazeiras, v. 2, n. 2, 217-234, jun/dez. de 2017. 
Conceição Lima, Paulina Chiziane e Odete Semedo, alguns de muitos exemplos de uma literatura que não deixa de tatear o feminino.

No âmbito político temos, semelhantemente, vozes como as de Adelaide Cabete (1867-1935), pioneira em Portugal na reivindicação do direito de voto e da licençamaternidade, a que se juntaram os esforços de Natália Correia, poeta e deputada que em meados do século XX advogou a favor das questões femininas, a que se sucedem Isabel Pires de Lima, Ministra da Cultura e deputada; Maria João Bustoff, Vice-ministra da Cultura; Ana Jorge, Ministra da Saúde, e, como representante da nova geração, Assunção Cristas, Ministra da Agricultura, Mar, Ambiente e Ordenamento do Território.

No Brasil, a inserção feminina tem sido constante, a partir de nomes como Nísia Floresta e Berta Lutz pioneiras na luta pela inserção através do voto e do trabalho; de Anita Malfatti e Tarsila do Amaral que alavancaram o Modernismo através da arte, a Luiza Erundina, nordestina eleita primeira prefeita de São Paulo, a maior cidade da América Latina. A estas se somam Marta Suplicy, Marina Silva, Heloísa Helena, que de cargos municipais galgaram posições em outros âmbitos do governo. O maior exemplo, contudo, apesar de partir de certa sustentação masculina, é o da presidente Dilma Rousseff ao suceder Luiz Inácio Lula da Silva. Naquele governo, Dilma assumiu a chefia do Ministério de Minas e Energia e da Casa Civil, até que, em 31 de outubro de 2010, tornou-se a primeira mulher a ser eleita para o posto de chefe de Estado e de Governo, na história do Brasil e da lusofonia.

Os exemplos acima são pequenos ao longo da história das sociedades capitalistas, mas intensos se analisarmos o curto tempo de surgimento das mulheres com poder na política. Desse modo, valendo-se da proposta de Walter Mignolo de que histórias "locais" são capazes de representar o "global", partir do pioneirismo de Luis António Verney e suas propostas de inclusão da mulher até chegarmos ao intenso debate sobre sua penetração nos meios sociais, sobretudo naqueles associados ao poder. Mais ainda, podemos afirmar que a cultura da nação-Estado, local ou global, perpassa a educação e esta, os currículos, o que nos conduz às proposições de Costa et ali (2003) sobre as grades curriculares como espaços de reprodução de cultura. É a partir daí que, acreditamos, torna-se de suma importância tratar, cuidar, rever o imaginário, as representações que delineiam a subjetividade acerca das relações sociais em seus 
diferentes espaços para a reorganização da sociedade como justa, laica, sustentável e equitativa.

\section{À guisa de conclusão}

Voltando ao romance de José Saramago, vemos que ao ficcionalizar o tecido histórico português, o escritor nos apresenta um texto que parte de um cenário de dominação feminina para a descrição de um ciclo em que ela cresce e se emancipa, deixando de ser sombra, como Sara, aprendendo a participar dos eventos, como Faustina, a deparar-se com a morte, tal qual ocorre com Gracinda, até "tornar-se o tema das histórias dos homens", como Maria Adelaide (SILVA, 1989, p. 259). Daí que, reafirmamos, a semântica dos "Mau Tempo" cede espaço ao sobrenome "Espada" que passa a determinar o destino desta personagem e dos que dela descendem, em um eixo condutor dos novos tempos ocasionados após Abril de 1974 e que perduram aos nossos dias. Desse modo, Saramago faz reviver os documentos sem os quais a história não é possível, acrescentando elementos iconográficos, étnicos integrantes de uma ambiência lendária que, calcada na memória social, perpetua e preserva tradições que nos ajudam a desvendar enigmas passados, recuperando propostas como as de Verney e Boaventura Santos ao longo dos diversos desdobramentos da história de Portugal.

Somada a esse viés literário, a perspectiva analítica nos conduz à ideia de historicidade associada ao panorama lusófono através da descrição de fatos visíveis, mas também pela atribuição de valor à produção do invisível relacionada ao gênero nos diferentes espaços da sociedade.

Enfim, a produção de subjetividades depende ainda de aprofundamentos acerca do gênero através de análises críticas e da interdisciplinaridade que perpassa os estudos culturais. Entendemos que este é um caminho a ser feito para o enfrentamento da questão e sua relação ética e política em prol da superação do reducionismo que ainda circula em nossos dias, ora no espaço meramente doméstico, ora no acadêmico e cultural, na justificativa biológica ou social.

O trabalho científico ainda carece desta articulação interdisciplinar. 


\section{Referências:}

BARLETTO, Marisa; CRUZ, Driely Cássia da; LOPES, Maria de Fátima Lopes. "Mulheres na universidade: construção de projetos e escolha profissional de estudantes de Pedagogia". In: Actas do VII Simpósio Nacional de Investigação em Psicologia Universidade do Minho, Portugal, 4 a 6 de Fevereiro de 2010.

COSTA, Marisa Vorraber; SILVEIRA, Rosa Hessel; SOMMER, Luis Henrique. "Estudos culturais, educação e pedagogia". Revista Brasileira de Educação.

Maio/Jun/Jul/Ago $2003 \mathrm{~N}^{\circ} 23$.

DUTRA, R. L. Literatura e ancestralidade: perspectivas interdisciplinares. In: Novikoff,C.; GRINSPUN, M. P. Z.; DUTRA, R.(Orgs). Desafios da práxis educacional: interdisciplinaridade, estética e ética. Salvador : Editora Pontocom, 2013.

JAPIASSU, Hilton e MARCONDES, Danilo. Dicionário básico de filosofia. Rio de Janeiro, Jorge Zahar Editores, 1994.

LAVINAS, Lena. Empregabilidade no Brasil: inflexões de gênero e diferenciais femininos. Texto para discussão $\mathrm{N}^{\circ}$ 826. Ministério do Planejamento, Orçamento e Gestão; Instituto de Pesquisa Econômica Aplicada (IPEA), 2001.

LESSA, Patrícia. Mulheres à venda: uma leitura do discurso publicitário nos outdoors. Londrina: Eduel, 2005.

MESSANOS. Márcia Rejane. Os Estudos Feministas de Mídia: uma trajetória angloamericana.In:http://www.pucrs.br/famecos/pos/cartografias/marcia_genero_29_07_06. php\#referencia>. Acesso em 10 de janeiro de 2011.

MIGNOLO, Walter. Histórias locais, projetos globais. Belo Horizonte: UFMG, 2003.

MILANEZ, Nílton. "A disciplinaridade dos corpos: o sentido em revistas". In: SARGENTINI, Vanice; NAVARRO-BARBOSA, Pedro (Org.). Foucault e os domínios da linguagem: Discurso, poder e subjetividade. São Carlos: Claraluz, 2004.

RECTOR, Mônica. "Luis António Verney e a prosa didática". In: O Marrare, ano 2, No. 3. Rio de Janeiro, outubro de 2002, p. 69-80. 
SANTOS, Boaventura de S. A crítica da razão indolente: contra o desperdício da experiência. São Paulo: Cortez, 2000.

SCHIEBINGER, Londa. O feminismo mudou a ciência? Bauru: EDUSC, 2001.

SCOTT, Joan W. “Gênero: uma categoria útil de análise histórica”. In: Educação e Realidade, vol. 16, no. 2, Porto Alegre, jul./dez. 1990.

"História das mulheres". In: BURKE, Peter. (org.) A Escrita da história: novas perspectivas. São Paulo, Unesp, 1992.

SARAMAGO, José. Levantado do chão. Lisboa, Dom Quixote, 1979.

SILVA, Teresa Cristina Cerdeira da. José Saramago - entre a história e a ficção: uma saga de portugueses. Lisboa, Dom Quixote, 1989.

VERNEY, Luis António. Verdadeiro método de estudar. (org. António Salgado Júnior.), v. 1. "Estudos linguísticos". Lisboa, Sá da Costa, 1949.

YANNOULAS, Silvia. "Notas para a integração do enfoque de gênero na educação profissional". In: VOGEL, Arno. Trabalhando com a diversidade do PLANFOR: raça/cor, gênero e pessoas portadoras de necessidades especiais, São Paulo, Unesp, 2001. 